\title{
How is it possible to profit from innovation in the absence of any appropriability?
}

\author{
Andrea Bonaccorsi ${ }^{1}$, Lucia Piscitello ${ }^{2}$,Monica Merito ${ }^{1}$, and Cristina Rossi ${ }^{2}$ \\ 1 DSEA-University of Pisa, Via Diotisalvi 2, 56126 Pisa, Italy \\ \{bonaccorsi,merito\}@sssup.it, \\ 2 DIG-Politecnico di Milano, Piazza Leonardo da Vinci 32, 20133 Milano, \\ Italy \\ \{lucia.piscitello,cristinal.rossi\}@polimi.it
}

\begin{abstract}
Open Source Software (OSS) represents an "open innovation" paradigm based on knowledge produced and shared by developers and users. New findings from a large survey of European software companies show that: (i) the OSS business model is currently involving almost one third of the industry, although with different intensity; (ii) compared with pure proprietary software producers, OSS firms have a broader product portfolio and are more diversified; moreover, (iii) OSS firms provide more complementary services to their customers; (iv) over time OSS firms increase the share of OS turnover out of the total turnover, becoming more and more OSS oriented; (v) both NOSS and OSS firms do not consider appropriability as a crucial requirement for innovation and do not consider the lack of appropriability as an obstacle to profitability.
\end{abstract}

Open Source (OS) software is now booming. More and more users are running open programs on their systems, and several OS solutions have turned out to be extremely successful (e.g., the Open Source Web server Apache). Such a bright demand together with the availability of software of good technical quality has stimulated firms' involvement in the OS movement. The new production paradigm has progressively acquired increasing importance within the software industry. Large incumbents like IBM, Hewlett Packard, Compaq, and Sun Microsystems have decided to release their source code to the community [1]. Furthermore, particularly after the drawing up of the Open Source Definition in 1998, many new software firms have entered the market, trying to profit not from traditional license fees but from other softwarerelated services [2]. Bonaccorsi et al. [3] have examined in great detail these companies finding that the large majority of them follow what they call a "hybrid" business model (as opposed to a pure OS model) by mixing products, types of licenses, and sources of revenues. Using a large dataset on software companies (NACE code 72, computer and related activities) based on a field survey in five European countries (Finland, Germany, Italy, Portugal, and Spain), we find strong evidence supporting this view.

The offering profiles of the 769 respondents take place along a continuum ranging from the exclusive provision of proprietary solutions to a product portfolio entirely based on OS. In particular, $66.8 \%$ of the firms supply only proprietary products and/or services, whereas only 19 provide just OS solutions. Of the $236(30.7 \%)$ firms supplying both types of software, a large fraction (38.1\%) claim to provide open

Please use the following format when citing this chapter:

Bonaccorsi, A., Piscitello, L., Merito, M., and Rossi, C., 2006, in IFIP International

Federation for Information Processing, Volume 203, Open Source Systems, eds. Damiani, E., Fitzgerald, B., Scacchi, W., Scotto, M., Succi, G., (Boston: Springer), pp. 333-334 
source and proprietary software with no distinction. Among companies supplying also OS based products and services (OSS firms), the proportion of sales generated by open software increases over time. Between 2000 and 2003, the percentage of respondents whose OSS turnover is above $50 \%$ has increased from $17.25 \%$ to $25.49 \%$, while those who work with OSS without generating revenues out of it have decreased from $33.33 \%$ to $10.98 \%$. If the OSS business model were not sustainable, we would not observe such an increase.

Compared with pure proprietary firms, OSS firms have a broader product portfolio, as measured by the number of product areas in which the firms are active. The majority of the firms working with proprietary software are active mainly in management and data management software while no other applications involve more than one third of them. In addition, compared with pure proprietary firms, OSS firms provide more complementary services to customers, as measured using a detailed taxonomy derived form the literature [1]. This corroborates the hypothesis that the increase in the number of product supplied is made possible by the exploitation of the open knowledge base created by the community of developers.

Data also show that, OSS firms do not consider the lack of appropriability as an obstacle to profitability and do not consider appropriability as a crucial requirement for innovation. Both OSS and proprietary firms agree that patents are costly $(72.55 \%)$, do not constitute a valid barrier to entry $(71.70 \%)$, and need a too long legal procedure $(68.81 \%)$. Such negative effects are not compensated by their capacity of providing incentives to innovators (only $32.09 \%$ ). These results are in line with the literature claiming that patents increase the cost of innovations while the impact on the expected revenues may be dubious [4]. In general, respondents have a more positive attitude towards licenses. However, the percentage of respondents agreeing that licenses are an appropriate mean of marketing products and recovering $R \& D$ investments is decreasing with the degree of openness of the firm.

1. Wichmann, T., 2002. Firms' Open Source activities: motivations and policy implications. International Institute of Infonomics, Berlecom Research $\mathrm{GmbH}$, Maastricht.

2. Hawkins, R.E., 2004. The economics of the Open Source Software for a competitive firm. Why give it away for free?. Netnomics 6, 103-117.

3. Bonaccorsi, A., Giannangeli, S., Rossi, C., 2006. Entry strategies under dominant standards. Hybrid business models in the Open Source software industry. Management Science, forthcoming.

4. Levin, R.C., Klevorich, A.K., Nelson, R.R., Winter, S.G., 1987. Appropriating the returns from industrial research and development. Brookings Papers on Economic Activity 3, 783-820. 